\title{
Malaria related myalgia-arthralgia: an imported case report treated with anti-malarial drug
}

\author{
Forman E. Siagian' ${ }^{1 *}$, Ronny ${ }^{1}$, Apriani I. Sirra², Urip Susiantoro1, Melsipa Siregar1
}

\author{
${ }^{1}$ Department of Parasitology and The Centre of Biomedic Research, ${ }^{2}$ Faculty of Medicine, Universitas Kristen \\ Indonesia, Jakarta, Indonesia
}

Received: 20 August 2020

Accepted: 28 August 2020

\section{*Correspondence:}

Dr. Forman E. Siagian,

Email: forman.siagian@uki.ac.id

Copyright: () the author(s), publisher and licensee Medip Academy. This is an open-access article distributed under the terms of the Creative Commons Attribution Non-Commercial License, which permits unrestricted non-commercial use, distribution, and reproduction in any medium, provided the original work is properly cited.

\begin{abstract}
Malaria is still a major health problem in Indonesia, especially in endemic areas. We present an imported case of malaria with prominent subjective complaint of the patient is in the form of persistent muscles and joints pain. A 21 years old female with complaint of intermittent fever and persistent muscle joints paint since one week before seeing a doctor. She had history of repetitive attack of malaria tropica. Physical examination in general showed no clear derangements, but on thick and thin blood smear stained with Giemsa revealed malaria falciparum $(+)$. Combo therapy of antimalarial drug soon be given and the patient healed with the disappearance of all previous complaint. Myalgia and arthralgia in case of malaria falciparum (+) might be the earliest subjective sign of rhabdomyolisis, a potentially fatal and lethal complication of malaria.
\end{abstract}

Keywords: Imported malaria, Febrile, Fever, Muscle, Pain, Combotherapy

\section{INTRODUCTION}

Malaria is a blood protozoan parasitic infection caused by the bite of a female Anopheles spp mosquito. In human, there are 5 species of Plasmodium, namely Plasmodium flaciparum, $P$. vivax, $P$. ovale, $P$. malariae, and $P$. knowlesi. ${ }^{1}$ The disease is most prevalent in Sub Saharan Africa and Southeast Asia, including Indonesia., ${ }^{2,3}$ Its global morbidity and even mortality still high, especially in the endemic area. Pregnant women and children are the most vulnerable group, but also travellers traveling to tourist areas which is considered as high transmission; the latter categorized as imported malaria, especially when the infection manifests in malarial free area, e.g. Jakarta. ${ }^{4,5}$

In general, malaria causes several subjective complaints from the patients, including fever, chills, malaise, headaches, and myalgia etc. Muscular complaint is not always prominent. In severe form of malaria falciparum, although very rare, a condition of rhabdomyolysis with myoglobinuria and skeletal muscle necrosis can occur; sometime it precede renal failure secondary to acute tubular necrosis, a very fatal complication of untreated malaria falciparum. ${ }^{6}$ Here we present a case of malaria with prominent subjective complaint of the patient is in the form of persistent muscles and joints pain.

\section{CASE REPORT}

A 21 years old female medical student, who just recently returned from her hometown Timika, Papua and coming back to Jakarta at mid of July 2020, suffer from high fever with chills, headache and muscle pain. About 1 week prior seeing the doctor in the Department of Parasitology at July 28th 2020, she started suffer from an intermittent high fever that occur every 48 hours or less, but the interval between temperature rises and drops 
irregular, showing no clear distinct periodicity. The fever may reach $38.5^{\circ} \mathrm{C}$ at the highest point accompanying with chills and massive sweating profusely, then afterward the temperature return to normal and the patient felt better.

Besides fever, the most prominent complaint is persistent muscle pain, in her word she uses the phrase "like she was beaten all over her body, and the pain was felt to the joints and bones" This muscular pain complaint being felt since the beginning of the first episodes of fever, and did not reduced, even when the temperature back to normal. During the rise of the temperature she also had headache. The patient took paracetamol $500 \mathrm{mg}$ to relieve the complaint but the result was not satisfactory. The patient had history of repeated attacks of malaria, which she remember as malaria tropica, which she had experienced since she was still in elementary school (she was living in Timika since she was born, and just leave her hometown when she enter medical school in Jakarta, Indonesia 3 years ago; this complaint showed up repetitively, especially when she had fever). Beside fever and musclejoint pain, she does not complain about any problems in other systems (e.g. no cough or out of breath, no GI tract disturbance etc). The patient consumes paracetamol 500 $\mathrm{mg}$ in order to relief the fever and the muscle pain, but it just not working.

During physical examination, in general appearance/ status generalisata, she looked moderately ill with vital sign as follows: temperature $38.5^{\circ} \mathrm{C}$, respiratory rate $20 \mathrm{x} /$ minute, heart rate $84 \mathrm{x} /$ minute, and blood pressure 110/80 mmHg. The patient's height and weight: 158 $\mathrm{cm} / 63 \mathrm{~kg}$.

On her status localis (her upper and lower extremity muscle) the muscle strength 5555 in all extremity, range of movement good and unlimited, muscle pain/myalgia $(+)$; but during the examination, the examiner discover about joints pain/arthralgia (+). Beside the muscles and joints complaint, all the other systems were within normal limits and there were no signs of anemia (e.g pallorness seen over lower conjuctiva pars palpebra, angular cheilitis or koilonichia).

Considering she had history of chronic and repetitive episodes of malaria tropica, a malaria blood examination immediately recommended, and all of these procedures conducted in the laboratory the dept. of Parasitology, faculty of Medicine, Universitas Kristen Indonesia Jakarta, Indonesia. The first blood sample taken on July $28^{\text {th }} 2020$, the second consecutive was withdrawn on July $29^{\text {th }} 2020$ and the third on August the $4^{\text {th }} 2020$. The patient has a fever at the first and second blood sampling. Thin and thick blood smear directly made from the blood taken and were smeared with Giemsa stain (Figure 1).

As soon as the diagnosis malaria falciparum confirmed, the patient was asked to be hospitalized, so that antimalarial drugs can be administered cito. The reasons for hospitalization suggestion primarily was because in non- malarial endemic areas of Indonesia like Jakarta, antimalaria drugs available on a limited basis and it can only be obtained through the provincial health office as the government policy; and in order to get that medicine, the patient must be admitted to the hospital and hospitalized. But unfortunately, the patient refused to be admitted to the hospital.

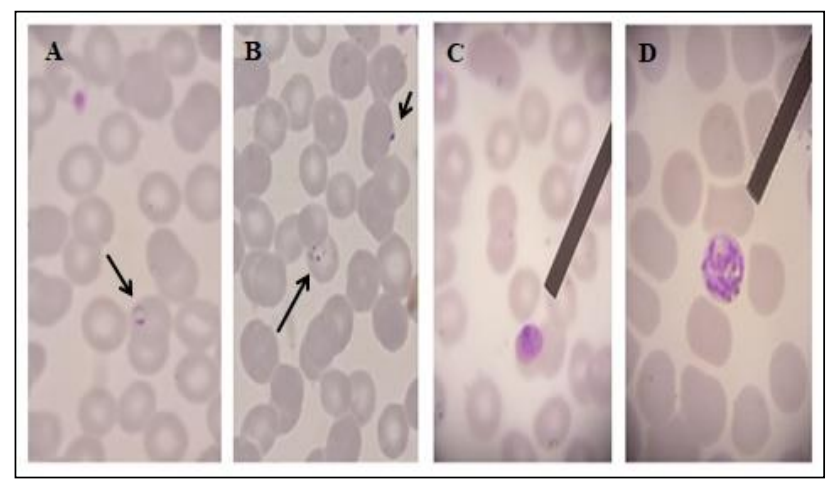

Figure 1: Thin blood smear of malaria positive case with causative agent $\boldsymbol{P}$. falciparum . (A) Ring form appearance of immature trophozoite $\boldsymbol{P}$. falciparum, (B) accole appearance and double dots appearance of immature tropozhoite $P$. falciparum, (C) developing gametocyte of $\boldsymbol{P}$. falciparum, (D) mature schizont of $\boldsymbol{P}$. falciparum.

The slide (A) and (B) came from the first blood sample (July 28th 2020) while slide (C) and (D) came from the second blood sample (July 29th 2020).

Beside refusal of hospitalization, patient also refuses to have a routine blood examination (hemoglobin, hematocrit, thrombocyte, leukocyte, differential count) and also routine urinalysis due to the financial limitation.

The patient refuses to be hospitalized and prefer to be out patient because the patient is right in the middle of her final examination and despite her clinical condition, the patient reassure the doctor that she still can withstand all the complaint and willingly to have her blood taken to be re-examined exactly just as the doctor instruction, to check the patient responded to therapy. She said that she always bring anti-malaria medicine wherever she goes because she already suffer malaria since elementary school.

So immediately right as the doctor's instruction, the patient start taking combo therapy of dihydroartemisinin $40 \mathrm{mg}$ and piperaquine phosphate $320 \mathrm{mg}$ (D-ARTEPP®, Guilin Pharmaceutical Co., Ltd, China Batch no. SQ190801, mfg. date 05/08/2019, exp. Date 04/08/2021). The dosage of regimen is based on weight for 3 days consumption (D0, D1 and D2) with maximal adjusted dose recommended for her as many as $1 \times 3$ tablets for patients weighing $\geq 41 \mathrm{~kg}$, just as the manufacturer's instruction. Another name for this preparation namely DHP. For supporting DHP, treatment was as for arm dihydroartemisinin piperaquine, a single dose of primaquine (PQ) tablets of $0.75 \mathrm{mg} / \mathrm{kg} \mathrm{BW}$ was provided 
on day-3 using $15 \mathrm{mg}$ base PQ tablets (local Indonesian product by PT Phapros, Tbk. Semarang, Indonesia). Additional generic Paracetamol 500 mg given pro renata.

The patient testifies, muscles and joints pain complain reduced significantly after she has taking the first medication (day 1) of combo therapy DHP. The next day (day 2) after having the second regimen, all complain, including fever, pain, headache and chills diminished. She continues to have the DHP until the third day (day 3) where she said that she already feel better and recover. Analgesics and antipyretics Paracetamol $500 \mathrm{mg}$ taken PO 3 times only in the first day, but Paracetamol alone prior to anti-malarial administration could not reduce the muscle or joints pain.

The result of parasitology examination on the third blood sampling revealed there is no more viable parasite on her peripheral blood, and we confirmed the result of the third examination was malaria negative. She already recovers and healed after having and completing antimalarial drug.

\section{DISCUSSION}

Myalgia and arthralgia in this malaria positive patient involves unspecific group of muscle and joint, with or without any movement activity. Considering our patient complaint, this persistent myalgia, even though subjective, cannot be ignored nor underestimated, because it might be the earliest sign of rhabdomyolisis. ${ }^{6,7}$ Actually, there is little information available on the incidence of asymptomatic rhabdomyolysis in non-severely ill patients because no population-based studies have been performed. $^{8}$

Actually, to our knowledge, cases of malaria with the involvement of muscle and joints, causing muscle-joints pain, was rarely reported. Theoretically, during active malaria infection, circulatory changes occur in the host's microvasculature, consisting of increased viscosity, obstruction of capillaries with agglutinated and ruptured part of erythrocytes and, sometimes to some extent, intravascular coagulation formed. These series of event lead to a definite changes that can cause skeletal muscle necrosis with myoglobinuria. ${ }^{7}$ The release of myoglobin from damaged myocytes is central to the complex pathogenesis of rhabdomyolisis induced by the parasite malaria directly with the interfere from the immune complex. ${ }^{6}$ The diagnosis is based on high serum level of muscular enzymes; creatine phosphokinase (CPK) and in combination with previous clinical symptoms like myalgias. $^{9}$ Additional sign consist of sequestration of red blood cells and reduced muscle content of essential contractile proteins are some of the potential biomarkers of the predictor damage levels of skeletal and cardiac muscles, as the study by Marrelli et al revealed underlying molecular mechanisms of malaria-induced muscle damage, targeting key molecules, such as genes and lipids, associated and leading to muscle damage. These biomarkers might be useful for prevention of long-term complications and determining the effectiveness of interventions designed to protect cardiac and skeletal muscles from malaria-induced damage. ${ }^{7,10}$

Unfortunately, in this case, the patient refuses the suggestion of further blood and urine analysis. Checking blood creatine kinase (CK) level or urine myoglobin level measurement might be important and useful tools to detect any sign of rhabdomyolisis in malaria. But by improvement of clinical condition and loss of subjective complaint soon after the anti-malaria drug administered, it can give us a clue that in this case, rhabdomyolisis did not occur. The patient's good response to therapy also showed us that the parasite is still susceptible and prone to combotherapy. Active controlling of the presence of antimalarial drug in the community is one way to prevent drug resistance. ${ }^{11}$

Furthermore, it is also hard and complicated to establish the source of this malaria falciparum positive case that we reported. Our limitation is due to our inability to reliably classify the patient based on her outcomes and, specifically, to distinguish whether the patient suffer from recrudescence (i.e, P. falciparum malaria due to real previous antimalarial therapy failure) or from re-infection (i.e., due to new transmission caused by infectious mosquito bites during her returned home at the period of social restrictions imposed by the Indonesian government due to Covid-19) or simply just due to relapse (i.e., due to reactivation of dormant parasites that reside in the liver) in patients experiencing recurrence. But whatever the source, in this case, fortunately the patient responded well to anti-malaria combotherapy.

\section{CONCLUSION}

Our case emphasizes the growing concern of muscular manifestations of Malaria falciparum. To the best of our knowledge, this might probably the earliest subjective warning to rhabdomyolisis occurring as a complication of malaria tropica or malaria falciparum.

\section{ACKNOWLEDGEMENTS}

Thanks to Dr. Charles Mesang, Dr. Ribka Tjiptaning P (AAK), Dr. HR Agung Laksono, Dr. Hj Indrawati Sukadis, (M.Si) Dr. Yenni Tan, (MARS) whom collectively supported funding for fast track publication of this manuscript.

\section{Funding: No funding sources \\ Conflict of interest: None declared \\ Ethical approval: Not required}

\section{REFERENCES}

1. Antinori S, Galimberti L, Milazzo L, Corbellino M. Biology of Human Malaria Plasmodia Including Plasmodium Knowlesi. Medite J Hemato Infec Dise. 2012;4:e2012013. 
2. Talapko J, Škrlec I, Alebić T, Jukić M, Včev A. Malaria: The Past and the Present. Microorganisms. 2019;7(6): 179.

3. Sitohang V, Sariwati E, Fajariyani B, et al. Malaria elimination in Indonesia: halfway there. Lancet Glob Health. 2018;6(6):604-6.

4. Tizifa A, Kabaghe N, McCann S, van den Berg H, Van Vugt M, Phiri KS. Prevention Efforts for Malaria. Curr Trop Med Rep. 2018;5(1):41-50.

5. Lederman E, Sutanto I, Wibudi A, Ratulangie L, Rudiansyah I, et al. Imported Malaria in Jakarta, Indonesia: Passive Surveillance of Returned Travelers and Military Members Postdeployment. J travel med. 2006;13:153-60.

6. Reynaud F, Mallet L, Lyon A, Rodolfo M. Rhabdomyolysis and acute renal failure in Plasmodium falciparum malaria. Nephro Dialysis Transplant. 2005;20(4):847.

7. Marrelli M, Brotto M. The effect of malaria and antimalarial drugs on skeletal and cardiac muscles. Malaria J. 2016;15.

8. Siqueira M, Alexandre A, Mourão P, Santos S, Nagahashi K, Alecrim G, Lacerda V. Severe rhabdomyolysis caused by Plasmodium vivax malaria in the Brazilian Amazon. J Trop Med Hyg. 2010;83(2):271-3.

9. Nance R, Mammen L. Diagnostic evaluation of rhabdomyolysis. Muscle Nerve. 2015;51(6):793-810.

10. Marrelli T, Wang Z, Huang J, Brotto M. The skeletal muscles of mice infected with Plasmodium berghei and Plasmodium chabaudi reveal a crosstalk between lipid mediators and gene expression. Malar J. 2020;14;19(1):254.

11. Boni F, White J, Baird K. The Community As the Patient in Malaria-Endemic Areas: Preempting Drug Resistance with Multiple First-Line Therapies. Plos Med. 2016;13(3):e1001984.

Cite this article as: Siagian FE, Ronny, Sirra AI, Susiantoro U, Siregar M. Malaria related myalgiaarthralgia: an imported case report treated with antimalarial drug. Int J Basic Clin Pharmacol 2020;9:1603-6. 